\title{
Literature
}

Emmet, A. M. 1991: The Scientific Names of the British Lepidoptera - their History and Meaning. — Harley Books, Colchester, 288 pp. ISBN 094658936 6. Price GBP 24.95

Zoological nomenclature is an important scientific tool. It ensures, as the International Code emphasizes, that scientific names are universal and restrictive and thus can serve as the common language for scientists.

In Finland, the scientific names of the butterflies and moths have an additional, more practical function: the lepidopterans are almost invariably called by their Latin names, both by amateurs and professionals, in conversations and note books as well as in scientific meetings. Vernacular names have been formulated for all macrolepidopterous species, but they mainly serve the needs of the media.

A. Maitland Emmet's book is divided into four main sections: an introduction, a history of the scientific names of Lepidoptera, a systematic section, and appendices. The etymologies of the names are arranged according to the Log Book numbers of Bradley \& Fletcher (1986; An indexed list of British butterflies and moths) which are also, in a practical way, used in all cross references (as well as in this review). When required, the inflection of the Latin and Greek root words is given, and the Greek words are shown in both Greek and Roman letters. The book is a careful work: it is a miracle that there are so few printing errors in this kind of book.

Initially, treatment of the history and meaning of scientific names sounds like a boring subject. However, A. Maitland Emmet, who is well known from his handbooks on British microlepidoptera, was able to make this a highly inspiring and fruitful subject. As Prof. Sir Richard Southwood states in his foreword, the book was written "with infinite care and a remarkable blend of entomological and classical scholarship". Emmet's graduating in classical languages at Oxford and later teaching Latin and Greek for many years provided the necessary background for the present work. In hunting down the meanings of the names, Emmet also used his crossword addiction!

In the historical section, Emmet shows his wide knowledge of nomenclature, and writes about it in an attractive manner. I found the sections dealing with the history of generic names particularly interesting. Although, surprisingly, Emmet does not mention Anton Spannert's excellent book of 1888 (Die wissenschaftliche Benennungen der Europäischen Grosschmetterlinge, Berlin) he often refers to Spuler (19031910), who used most of Spannert's explanations (mentioned for example under Hyppa).

The systematic section offers a variety of readings: from simple linguistic explanations through complicated detective stories and charming mythological accounts to attractive essays (e.g. 1529 Hesperia). It is important to note that Emmet frequently consulted original descriptions (e.g. 1765 Cidaria Treitschke). Many times he reaches conclusions by taking into account certain authors' way of formulating names (e.g. 464 Plutella Schrank).

It is regrettable that Emmet followed, or possibly felt forced to follow, the non-classical and rule-breaking system of the Kloet \& Hincks checklist (1972) of not adjusting each specific name to fit the gender of the generic name. It is easy to guess that this has been a controversial practice for a classics scholar, as agreement of generic and specific names is a basic feature of the Linnaean binary system. The British way of interpreting the generic names as genderless and the adjective-specific names as nouns is quite artificial, in Roman terms "Barbaric"! Much grammatical advice is given in the Code. The argument cited by Emmet regarding taxonomists having "small Latin and less Greek" does not justify the destruction of the beauty and logic of the Linnaean method. 
It is often evident that Emmet's explanations approach art rather than science. Publishing them requires a lot of courage, because, of course, the results cannot always be appropriate. Thus, 14 Exoporia is not, as he claims, derived from a projection on the wing, but from an exoporian female genital opening (the root is poros = opening, not poros = stalactite, node etc.).

Emmet has corrected or at least given an alternative explanation for no less than $360 \mathrm{ex}$ planations proposed by Macleod (1959), revealing several anachronisms in Macleod's explanations, but once he probably falls into the same trap: I doubt that 2150 nebulosa would have shown melanism in Hufnagel's (1766) time, I think the grey colour with darker "clouds" and roundish spots is "cloudy" enough.

A good example of the amazing detective work of Emmet is in his noting that Linnaeus clearly had before him, when describing 2047 complana, a specimen of 2050 lurideola. This is entirely correct, because the syntypes in the Linnaean collection are of the species currently known as Eilema lurideolum (Zincken). For purposes of stability, a neotype will be designated by K. Mikkola \& R. Honey in a revision soon to appear (until the decision of the ICZN is rendered, the current usage must be followed).

One of the many merits of Emmet's book is the thorough presentation of entomologists whose names occur in the scientific names. Of course I found the story of R. Hast (see 1053 hastiana), a young, outstanding Finnish pupil of Linnaeus who died in his youth, particularly attractive. In this connection it should be noted that J. M. J. Tengström was a Finnish, not a Swedish lepidopterist. Authors who gave the names also received comments: I did not know for example that P. S. Pallas (1741-1811) was the first to record parthenogenesis (see 186 casta).

Emmet explains many names on the basis of geographical locations which have no entomological affinity. One wonders why 2369 Nonagria would not be derived from Lat. non + ager, agri = not-on-fields, or 2321 Apame $a$ from Gr. apamao $=$ to cut off.

In Appendix 3, Emmet lists 36 unresolved names; some of these do not seem unsur- mountable. The only (!) unclear Linnaean name, salmachus, which was suppressed by the international commission in favour of 373 tipuliformis Clerck, seems already to be explained under 1573 artaxerxes ssp. salmacis. Salmacis prayed to the gods to fuse her body with her lover's, and a hermaphrodite arose; tipuliformis resembles a combination of lepidopteran and hymenopteran bodies. Perhaps in this case a male hymenopteran fused with a female lepidopteran, therefore the masculine form. Macleod's explanation for 2111 Spaelotis, cave-dweller, seems correct except that the name does not concern larvae but adults which during aestivation creep into hollows, into human dwellings and so on. There are two geographic names among the unknowns: 1453 Pima is an AmerIndian tribe and locality name from Arizona (P. fosterella was actually described by Hulst from Colorado), and 222 yildizae is derived from a bay near the Dardanelles in Turkey. The name of the noctuid 2180 crini is derived from Crinum (Amaryllidaceae); the larva lives on bulbous plants. 2465 Tyta might be a femininized form of Gr. tyto = owl (J. H. Marshall, see Antenna $15: 154,1991$, offered the same opinion), perhaps because of the two white wing-patches which in the resting position look eye-like.

The few flaws mentioned above together compromise only a minimal part of Emmet's book. To notice them actually required many evenings of leafing through the explanations with great satisfaction and contentment. In fact, points of discussion and improvement stem from the nature of such a book. In Finland, we of course regret the absence of our purely northern and eastern species; for instance the mythology of the Thunberg names would have added a welcome gust of ancient Scandinavian wind to the mainly Greek and Roman stories.

A. Maitland Emmet's book is a giant work, written with humanistic and entomological sophistication. It is an inexhaustable source of reading. Simply, it is a treasure! I hope that many lepidopterists enjoy it and obtain from it a fresh new perspective on scientific nomenclature.

\section{Kauri Mikkola}

